\title{
Monitoring Biological Invasions in Freshwater Habitats
}

\author{
Montserrat Vilà and Emili García-Berthou
}

\section{Introduction}

Biological invasions of freshwater habitats are due to the accidental or deliberate introduction of organisms associated to aquaculture, sports fishing, passive transport by vessels, ornamental uses and man-made canals and corridors. In European freshwater habitats, about 296 species of alien invertebrate, mostly crustaceans, and 136 species of alien fish have been introduced (Gherardi et al. 2009). Inland surface waters have also been invaded by 444 species of alien plant (Lambdon et al. 2008). Fish have attracted most attention and the majority of these have originated from Asia, North America or within Europe (e.g. from southern to northern countries). Many aquatic alien species are widely distributed in Europe: the brook trout Salvelinus fontinalis in 26 countries; the crayfish Pacifastacus leniusculus in 25; the zebra mussel Dreissena polymorpha in 22. Among plants, the Canadian pondweed Elodea canadensis is the most widespread, being present in 36 countries (http://www.europe-aliens.org/).

Alien species invading freshwater systems are causing loss and degradation on all levels of biological organization from genes to populations and with cascading effects to entire ecosystems. One of the best-known European examples of genetic loss is the hybridisation between the native rare white-headed duck Oxyura leucocephala and the American ruddy-duck O. jamaicensis, the hybrids of which are very aggressive (Muñoz-Fuentes et al. 2007). Hybridization between native and alien species is occurring in other taxa such as plants (Spartina), crayfish (Orconectes), snails (Melanoides) and fish (Salmo). Invasions can also cause synergic

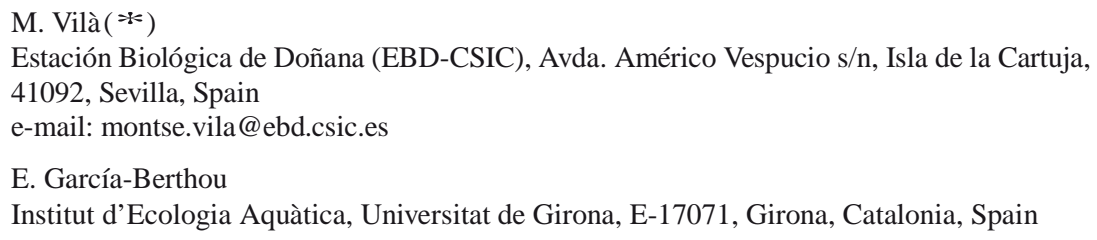


changes in nutrient cycling as well as habitat modification and alteration of hydrologic regimes. To cite a couple of examples, the red swamp crayfish Procambarus clarkii is usually the largest invertebrate in the invaded habitats and often exists in high densities; P. clarkii is an engineer species as its omnivory causes changes in carbon and nutrient pools and fluxes (Gherardi 2007). The coypu, Myocastor coypu, strongly disturbs the vegetation dynamics in freshwater habitats through grazing, and their burrowing activity can undermine riverbanks (Bertolino and Genovesi 2007). At the regional scale, invasions are causing the homogenisation of the flora and fauna. For example, in the last century, the fish fauna in the Iberian Peninsula river basins has increased in similarity by $17 \%$ compared to its native situation (Clavero and García-Berthou 2006).

Many alien species are causing socioeconomic impacts by interfering with water and fishery production, with commercial, industrial or even recreation activities (Vilà et al. in press). Aquatic plants forming thick floating carpets exclude the opportunity for angling, and interfere with navigation. Control of Eichhornia crassipes in the Guadiana river in Spain has cost 6.7 M€ in 1 year (Andreu et al. 2009). Invading aquatic molluscs also interfere with above-mentioned leisure activities, fouling fishing and pipe industry equipment. For example, agencies and individuals have spent about $\$ 1$ billion over a decade mitigating the zebra mussel in the USA and the losses due to fish introductions (mostly freshwater) amount to $\$ 5.4$ billion (Pimentel et al. 2005).

Strategies to overcome the impacts of invasions can be categorized as prevention, early detection, direct management and restoration. Prevention and early detection are recommended as the best strategy, as they promote a rapid response to invasion. Direct management by removing, controlling or containing alien species is very expensive and is mostly unsuccessful, especially when the introduced species is well established and widely distributed (Hobbs and Humphries 1995). Finally, active or passive restoration after invader removal needs to be assessed for the purposes of adaptive management. In all these strategies monitoring plays an essential role both from the applied point of view and for understanding the invasion process. In this chapter we discuss the reasons for monitoring invasive species beyond their use as ecological indicators, and offer some guidance on the design of appropriate long-term monitoring schemes.

\section{Invasive Species as Ecological Indicators}

One of the conceptual challenges of invasion biology is to understand whether invasive species are a driver of biodiversity loss or a consequence of other mechanisms of environmental degradation such as habitat loss or pollution (Didham et al. 2005). In practical terms, however, both cases are good reasons to monitor invasive species. An increase in the abundance and occupancy of invasive species can be indicative of environmental degradation (Kennard et al. 2005). Many freshwater fish species that are invasive in Europe, such as common carp Cyprinus carpio, 
mosquitofish Gambusia holbrooki or the pumpkinseed sunfish Lepomis gibbosus, are so called 'tolerant' species, i.e. species sensitive "to any common impact related to altered flow regime, nutrient regime, habitat structure and water chemistry" (Pont et al. 2006). Therefore, the presence, increase in abundance or the area of occupation of these species will be indicative of environmental degradation. At the same time, these invasive species can also have direct ecosystem effects and consequences for biodiversity, although these are less well known. For instance, the common carp decreases the abundance of macrophytes directly by uprooting them and indirectly by increasing water turbidity (Lougheed et al. 1998), and the mosquitofish has been directly linked to the decline of native fishes and amphibians (Alcaraz et al. 2008). Therefore, monitoring invasive species is a good tool both for detecting other drivers of environmental degradation and for understanding their direct impacts on biodiversity and ecosystem processes.

Another good reason to choose invasive species as target species for monitoring is that introduced populations are generally of no conservation value - but rather the opposite. To study or monitor dangerous chemical substances such as pesticides or heavy metals, which is mandatory according to several European laws, freshwater organisms (often fish) need to be sacrificed. To this end, it is of less ethical concern and more practical to use invasive rather than native species. This explains why many invasive species such as mosquitofish (Mulvey et al. 1995), common carp (Solé et al. 2003) or zebra mussel Dreissena polymorpha (Chevreuili et al. 1996) are among the most studied in aquatic toxicology and water pollution monitoring.

\section{Other Reasons for Monitoring Invasive Species}

Although invasive species monitoring is quite developed in North America (Table 10.1), and some European countries such as France or the UK have comprehensive monitoring schemes for water quality, fish populations and water pollutants, specific programs for invasive species in Europe are less established. For example, recently, in the UK the Department for Environment, Food and Rural Affairs (DEFRA 2008), has acknowledged that despite the comprehensive monitoring schemes in the UK, these are inadequate for invasive species and has identified the development of detection and monitoring mechanisms as a key objective of its invasive species strategy. The European Water Framework Directive (DIRECTIVE 2000/60/EC) also establishes that all countries will routinely have to monitor biological quality elements (algae, invertebrates and fish) with standard methods in most water bodies in order to achieve a good ecological status. As such, this Directive could provide an excellent tool for assessing the status of invasive species and understanding their impacts. Long-term monitoring of biological invasions, that integrates information before, during and after an invasion provides valuable information for both managers and scientists. Some of the basic and applied uses of monitoring programs on biological invasions could be summarized as follows. 
Table 10.1 Worldwide examples of regional monitoring programs for freshwater invasive species

\begin{tabular}{lll}
\hline Name, Country and Internet link & Target invasive species & Objective \\
\hline $\begin{array}{l}\text { Invasive Plant Inventory, Monitoring and Mapping } \\
\text { Protocol, }\end{array}$ & $\begin{array}{c}\text { Aquatic and terrestrial invasive plant } \\
\text { species }\end{array}$ & $\begin{array}{c}\text { Abundance and spread of invasive species; } \\
\text { early detection and expansion }\end{array}$
\end{tabular}

U.S.D.A. Forest Service, USA, 1

Pennsylvania Aquatic Invasive Species Monitoring Squad

Pennsylania State, USA, 2

Aquatic Invasive Species Network,

Citizen Lake Monitoring Network

Wisconsin state, USA, 3

Doñana Biological Station, Spain, 4

Wiltshire River Monitoring Scheme

Wiltshire,

England, UK, 5

\section{Zebra mussel (Dreissena polymorpha)}

Quagga mussel (D. rostriformis bugensis)

Eurasian water-milfoil (Myriophyllum spicatum)

Curly-leaf pondweed (Potamogeton crispus)

Purple loosestrife (Lythrum salicaria)

Jellyfish (Craspedacusta sowerbyi) Zebra mussel (Dreissena polymorpha) Chinese mystery snail (Bellamya japonica) Banded mystery snail (Viviparus georgianus) Rusty crayfish (Orconectes rusticus)

Mosquito fern (Azolla filiculoides)

Red swamp crayfish (Procambarus clarkii)

Red-eared slider (Trachemys scripta elegans)

Giant hogweed (Heracleum mantegazzium)

Himalayan balsam (Impatiens glandulifera)

Japanese knotweed (Fallopia japonica)

Signal crayfish (Pacifastacus leniusculus)

Brown rat (Rattus norvegicus)

American mink (Mustela vison)
Abundance and spread of invasive mussels; early detection and expansion

Abundance and spread of invasive species; early detection and expansion

Abundance and spread; early detection and expansion

Early detection and expansion 
Zebra mussel monitoring, Catalan Water Agency and

1. http://www.wilderness.net/toolboxes/documents/invasive/FS_Inventory\&Map_Guide.pdf

2 http://www.pserie.psu.edu/seagrant/zm/monitor/MonitoringManual2008.pdf

3. http://dnr.wi.gov/lakes/clmn/

4 http://icts.ebd.csic.es

5. http://wsbrc.wiltshirewildlife.org.uk/RecordingSchemes/RiverMonitoring/PageTemplate.aspx

6. http://oph.chebro.es/DOCUMENTACION/Calidad/mejillon/en_inicio.htm

7. http://aca-web.gencat.cat/aca/appmanager/aca/aca?_nfpb=true\&_pageLabel=P1230354461208201714706

8. http://www.europe-aliens.org 


\section{Early Warning System}

Taxonomic monitoring programs conducted by experts can detect the presence of alien species. For this purpose, an ad-hoc list of potential alien species to survey would increase the survey efficiency. Such a list is usually based on alien species present in nearby habitats or on alien species common in similar habitat types. Updating this list and training non-expert manager teams in species identification allows for early detection of alien species while conducting other routinely field surveys not necessarily related to invasions.

Early detection of new foci of invasion is extremely useful for management, as eradication at this stage is usually non-expensive and feasible. Invasion prevention programs should be linked to monitoring the putative vectors of transport and introduction such as vessel traffic, fishing activities and other anthropogenic impacts that can influence alien propagule pressure. For this reason it is extremely useful to know for each sampling locality its connection to nearby water bodies through piping, canals or natural corridors. The benefits of connecting invader and vector monitoring include that it might prevent the arrival of invaders by interfering with transport vectors.

\section{Dynamics of Biological Invasions}

Spread rates of biological invasions are poorly known in freshwater habitats compared to marine and terrestrial environments. To date, reconstructions of the spreading of invaders have mostly been inferred from chronosequence analyses of snapshots of the presence of the invader in different locations. Surveillance can provide a time series of invaded and non-invaded sites to demonstrate the spread of the invader in real time, determining the metapopulation dynamics, identifying species constraints, detecting boom and bust cycles and time-lags between appearance and establishment, etc.

\section{Linking Invasions to Impacts and Habitat Resistance to Invasion}

Probably one of the longest surveillance programs assessing the effects of an invader on community structure is the zebra mussel project that has been conducted for more than $60 \mathrm{yr}$ in freshwater areas in the former Soviet Union (Karatayev et al. 1997). Quantifying the presence and abundance of invader and native species in conjunction with measuring water quality, disturbance level, habitat type, etc. allows for establishing correlations between the invasion degree, food-web alterations and environmental changes. Although such observational analysis does not demonstrate causality, as symptoms of invasion can be confounded by impacts, they are 
the baseline data from which to establish a hypothesis that can be tested by designing specific manipulative experiments.

\section{Identification of Synergies with Environmental Global Change}

Global change components (i.e. increased greenhouse gas emissions, climate change, water eutrophication, changes in land use, biotic homogenization) have typically been studied and managed in isolation. However, there are more and more examples indicating that water warming, increased hypoxia, altered flow regimes, higher salinity and changes in reservoir habitat temperatures can change invasion patterns (Rahel and Olden 2008). Monitoring the presence/absence and abundance of target invaders in combination with spatially-explicit information on $\mathrm{CO}_{2}$ and $\mathrm{CH}_{4}$ fluxes, climate parameters, nutrient loading and land use changes can be used to predict changes in invasion dynamics with environmental change (Lee et al. 2008) and make possible an appropriate management response.

\section{Assessment of Habitat Restoration After Direct Management}

Removal of an invader from an ecosystem represents a grand experiment testing the effect of a particular species on ecosystem processes. However, as removal usually requires some level of disturbance, we need long-term surveillance to avoid confusing recovery after invasion with habitat succession. Monitoring restoration should not only assess whether the population of the invader has been reduced but also if populations of native species have increased. Monitoring restoration is essential for adaptive management to set priorities among invaders, locations, timings and control treatments. Adaptive management may also be needed if the risk of invasion changes through time.

\section{Reinforcement of Public Outreach and Environmental Education}

Well-established long-term monitoring programs are based on standardised protocols. These protocols are sometimes inspired by common national or international initiatives, and allow partnership building and cooperation between agencies. This can provide an opportunity for replication and more powerful analysis. It can also offer the opportunity for rapidly training new professionals and for engaging non-experts in monitoring activities, therefore increasing the number of habitats sampled, resampling priority habitats or increasing the frequency of sampling (see several examples in Table 10.1). Monitoring programs can also be integrated into outreach conservation 
programs through education in summer schools, volunteer activities in natural areas, on-line education programs, etc.

\section{Designing an Appropriate Monitoring Scheme}

Obviously, the complexity of long-term monitoring programs will largely depend upon the taxa and the characteristics of the habitats. In many freshwater systems, such as large lakes and marshes, traditional field-based monitoring presents several challenges including inaccessibility to areas for sampling, temporal changes, and expensive equipment. Invasion by floating aquatic plants into huge areas best exemplifies this situation. The fern Azolla filiculoides is intermittently invading large areas of marsh in the Doñana National Park (Spain), an area very difficult to map due to its large size (25,000 ha). Recently, remote sensing by Landsat images has been used to identify the extent of $A$. filiculoides invasion and to detect seasonal and annual variability (Díaz-Delgado et al. 2008, Chapter 31 in this volume). However, to ascertain that the satellite multispectral imagery distinguishes between A. filiculoides and other vegetation such as sedges, ground-truthing by horse riding and aerial photograph analysis has been necessary.

Timing is also crucial both for monitoring and for management. Fish sampling, often by electrofishing, can be constrained by weather conditions or high flows. Fish populations are usually sampled during the same season each year, often in summer, to ensure the comparability of samples. Species-specific ecological features should be used to inform the sampling design: e.g. sampling for zebra mussel larvae is limited to the reproductive season (spring and summer); small organisms with shorter generation times (e.g. algae or invertebrates) should be sampled more often to detect early foci.

The methodology will also depend on whether the goal is to detect established invaders or to provide an early detection system. For example, early detection of the zebra mussel should focus on sampling the water column for the presence of larvae, rather than using fouling panels to count attached mussels. Taking reference samples of the first record is extremely important to provide a good estimation of the minimum residence time since introduction.

However, all of these monitoring and surveillance schemes are of little use if the data are not archived properly and cannot be easily retrieved in a "user-friendly" way. Whenever possible, the data should be integrated in larger biodiversity databases and information systems, preferably on the Internet.

\section{Conclusions}

Giving the unprecedented rate of introductions in freshwater ecosystems, monitoring should play a central role in the early detection of invaders and enabling a rapid management response. Furthermore, monitoring alien species in freshwater habitats 
allows us to explore the extent, dynamics, impacts and drivers of invasions. In order to relate invasion to impact and ecosystem vulnerability to invasion, the monitoring should be integrated with measurements of other physical, chemical and biological variables in the system. This information can also be related to spatially explicit GIS techniques to investigate the interactions with other drivers of global environmental change. As monitoring requires us to ascertain the extent of compliance with a pre-determined standard, it is as important to establish surveillance programs in locations where the invader is present as it is where it is absent, or across locations with a gradient of invader abundance. Scientifically, datasets accumulated by surveillance and monitoring are an important source of information valuable for answering many scientific questions, which can not be tackled by standard shortterm research projects and limited scientific man-power.

Acknowledgements We thank J. Andreu, A. Montero and R. Díaz-Delgado for comments on an early version of the manuscript. This review was partially supported by the Integrated European Project ALARM (contract 506675, http://www.alarmproject.net) to MV and the Spanish Ministry of Education (Project CGL2006-11652-C02/BOS) to EG.

\section{References}

Alcaraz C, Bisazza A, García-Berthou E (2008) Salinity mediates the competitive interactions between invasive mosquitofish and an endangered fish. Oecologia 155:205-213

Andreu J, Vilà M, Hulme PE (2009) An assessment of stakeholder perceptions and management of noxious alien plants in Spain. Environ Manage 43:1244-1255

Bertolino S, Genovesi P (2007) Semiaquatic alien mammals introduced into Italy: Case studies in biological invasion. In: Gherardi F (ed) Biological invaders in inland waters: Profiles, distribution, and threats. Springer, Dordrecht, pp 175-192

Chevreuili M, Blanchard M, Teil MJ, Carru AM, Testard P, Chesterikoff A (1996) Evaluation of the pollution by organochlorinated compounds (polychlorobiphenyls and pesticides) and metals (Cd, $\mathrm{Cr}, \mathrm{Cu}$ and $\mathrm{Pb}$ ) in the water and in the zebra mussel (Dreissena polymorpha Pallas) of the river Seine. Water Air Soil Pollut 88:371-381

Clavero M, García-Berthou E (2006) Homogenization dynamics and introduction routes of invasive freshwater fish in the Iberian Peninsula. Ecol Appl 16:2313-2324

Department for Environment, Food and Rural Affairs (DEFRA) (2008) The invasive non-native species framework strategy for Great Britain. Department for Environment, Food and Rural Affairs, London, p 42

Díaz-Delgado R, Bustamante J, Aragonés D (2008) La teledetección como herramienta en la cartografía de especies invasoras: Azolla filiculoides en Doñana. In: Vilà M, Valladares F, Traveset A, Santamaría L, Castro P (eds) Invasiones Biológicas. Colección Divulgación CSIC, Madrid, pp 159-163 (in Spanish)

Didham RK, Tylianakis JM, Hutchison MA, Ewers RM, Gemmell NJ (2005) Are invasive species the drivers of ecological change? Trends Ecol Evol 20:470-474

Gherardi F (2007) Understanding the impact of invasive crayfish. In: Gherardi F (ed) Biological invaders in inland waters: Profiles, distribution and threats. Springer, Dordrecht, pp 507-542

Gherardi F, Gollasch S, Minchin D, Olenin S, Panov VE (2009) Alien invertebrates and fish in European inland waters. In: DAISIE (eds) Handbook of alien species in Europe. Springer, Dordrecht, pp 93-104

Hobbs RJ, Humphries SE (1995) An integrated approach to the ecology and management of plant invasions. Conserv Biol 9:761-770 
Karatayev AY, Burlakova LE, Padilla DK (1997) The effects of Dreissena polymorpha (Pallas) invasion on aquatic communities in eastern Europe. J Shellfish Res 16:187-203

Kennard MJ, Arthington AH, Pusey BJ, Harch BD (2005) Are alien fish a reliable indicator of river health? Freshwater Biol 50:174-193

Lambdon PW, Pyšek P, Basnou C et al (2008) Alien flora of Europe: Species diversity, temporal trends, geographical patterns and research needs. Preslia 80:101-148

Lee H II, Reusser D, Olden JD et al (2008) Integrated monitoring and information systems for managing aquatic invasive species in a changing climate. Conserv Biol 22:575-584

Lougheed VL, Crosbie B, Chow-Fraser P (1998) Predictions on the effect of common carp (Cyprinus carpio) exclusion on water quality, zooplankton, and submergent macrophytes in a Great Lakes wetland. Can J Fish Aquat Sci 55:1189-1197

Mulvey M, Newman MC, Chazal A, Keklak MM, Heagler MG, Hales LJ (1995) Genetic and demographic responses of mosquitofish (Gambusia holbrooki Girard 1859) populations stressed by mercury. Environ Toxicol Chem 14:1411-1418

Muñoz-Fuentes V, Vilà C, Green AJ, Negro JJ, Sorensen MD (2007) Hybridization between white-headed ducks and introduced ruddy ducks in Spain. Mol Ecol 16:629-638

Pimentel D, Zuniga R, Morrison D (2005) Update on the environmental and economic costs associated with alien-invasive species in the United States. Ecol Econ 52:273-288

Pont D, Hugueny B, Beier U, Goffaux D, Melcher A, Noble R, Rogers C, Roset N, Schmutz S (2006) Assessing river biotic condition at a continental scale: A European approach using functional metrics and fish assemblages. J Appl Ecol 43:70-80

Rahel F, Olden JD (2008) Assessing the effects of climate change on aquatic invasive species. Conserv Biol 22:521-533

Solé M, Raldua D, Piferrer F, Barceló D, Porte C (2003) Feminization of wild carp, Cyprinus carpio, in a polluted environment: plasma steroid hormones, gonadal morphology and xenobiotic metabolizing system. Compar Biochem Physiol Part C Toxicol Pharmacol 136:145-156

Vilà M, Basnou C, Pyšek P, Josefsson M, Genovesi P, Gollasch S, Nentwig W, Olenin S, Roques A, Roy D, Hulme P, DAISIE partners. How well do we understand the impacts of alien species on ecosystem services? A pan-European cross-taxa assessment. Frontiers in Ecol Environ (in press) DOI: $10.1890 / 080083$ 